\title{
In vitro interaction of lumefantrine and piperaquine by atorvastatin against Plasmodium falciparum
}

\author{
Jérome Dormoi ${ }^{1,2,3}$, Hélène Savini ${ }^{2,3,4}$, Rémy Amalvict ${ }^{2,3,5}$, Eric Baret ${ }^{2,3,5}$ and Bruno Pradines ${ }^{1,2,3,5^{*}}$
}

\begin{abstract}
Background: There is an urgent need for the discovery of new anti-malarial drugs and combination therapy. A combinatorial approach protects each drug from the development of resistance and reduces generally the overall transmission rate of malaria. Statins, the inhibitors of 3-hydroxy-3-methylglutaryl-Coenzyme A reductase and a family of lipid-lowering drugs, have in vitro anti-malarial properties, and more specially atorvastatin. However, atorvastatin has a short elimination half-life (14 hours) and an efficient combination of anti-malarial drugs must associate a drug with a short elimination half-life and a drug with a long elimination half-life. The objective of the present work was to identify new potential partners among standard new anti-malarial drugs with long elimination half-life, such as lumefantrine, piperaquine, pyronaridine and atovaquone, to improve the in vitro activity of atorvastatin against different Plasmodium falciparum strains to treat uncomplicated malaria.
\end{abstract}

Methods: In vitro interaction of atorvastatin in combination with lumefantrine, piperaquine, pyronaridine and atovaquone was assessed against 13 P. falciparum strains by isotopic test.

Results: Atorvastatin showed additive effects with pyronaridine, piperaquine and lumefantrine. Atorvastatin increased the in vitro activity of lumefantrine and piperaquine at concentrations expected in clinical observations. The average $\mathrm{IC}_{50}$ values of lumefantrine decreased significantly from $31.9 \mathrm{nM}$ to $20.5 \mathrm{nM}$ (a decrease of 35.7\%) in combination with $1 \mu \mathrm{M}$ of atorvastatin.

Conclusions: Even though in vitro data indicate that atorvastatin improved the activity of lumefantrine and piperaquine, the same may not necessarily be true in vivo. Piperaquine, a new drug with long terminal elimination half-life, is currently a very promising anti-malarial drug.

Keywords: Malaria, Plasmodium falciparum, Anti-malarial, Resistance, In vitro, statin

\section{Background}

Over the past 20 years, many strains of Plasmodium falciparum have become resistant to chloroquine and other anti-malarial drugs [1]. In 2002, the World Health Organization (WHO) recommended that artemisininbased combination therapy (ACT) be used to treat all cases of uncomplicated malaria and that artesunate should be used as the first-line treatment for severe malaria in

\footnotetext{
* Correspondence: bruno.pradines@free.fr

'Unité de Parasitologie et d'Entomologie, Département de Microbiologie, Institut de Recherche Biomédicale des Armées, Brétigny sur Orge, France ${ }^{2}$ Unité de Parasitologie, Département d'Infectiologie de Terrain, Institut de Recherche Biomédicale des Armées, Marseille, France

Full list of author information is available at the end of the article
}

2011. Several recent studies have reported clinical failures or extended parasite clearance times in Cambodia [2-4].

There is an urgent need for the discovery of new antimalarial drugs and combination therapy. A combinatorial approach protects each drug from the development of resistance and reduces generally the overall transmission rate of malaria [5].

Statins, the inhibitors of 3-hydroxy-3-methylglutarylCoenzyme A reductase (HMG-CoA reductase) and a family of lipid-lowering drugs, have in vitro anti-malarial properties [6,7]. Moreover, atorvastatin improved the in vitro activity of mefloquine [8], quinine [9], dihydroartemisinin [10] and Proveblue ${ }^{\circ}$, a methylene blue preparation that complies with the European Pharmacopoeia 
and contains limited organic impurities and heavy metals of recognized toxicity [11], at the plasma concentrations expected in clinical observations in patients taking $80 \mathrm{mg}$ of atorvastatin daily $(0.1$ to $0.5 \mu \mathrm{M})$ [12]. However, atorvastatin used alone failed to prevent death from cerebral malaria or to affect the parasitaemia of infected mice [13-15]. Atorvastatin combined with mefloquine (a long half-life drug) led to a significant delay in mouse death and had an effect on the onset of cerebral malaria symptoms [16]. However, the mice died of severe anaemic malaria. The combination of dihydroartemisinin and atorvastatin was effective as a therapeutic scheme for improving mouse survival but less effective for cytokine modulation, which is associated with protection against cerebral malaria [17]. In a therapeutic intraperitonalscheme, the combination of atorvastatin and dihydroartemisinin versus dihydroartemisinin alone resulted in a significant delay in mouse death and had an effect on the onset of cerebral malaria symptoms and on the level of parasitaemia. The experimental conditions did not prevent death. Atorvastatin failed to improve in vivo efficacy of quinine in cerebral malaria [17]. Atorvastatin has a short elimination half-life (14 hours) compared to proguanil (24 hours), atovaquone (31-73 hours), chloroquine (two to three days), lumefantrine (four to six days), pyronaridine (six days), mefloquine (six to 41 days), or piperaquine (22 days). A combination of anti-malarial drugs must associate a drug with a short elimination half-life and a drug with a long elimination half-life. However, this is a debatable concept because the long half-life drug is exposed for a significant period of time to select parasite resistance.

The objective of the present work was to identify new potential partners among standard new anti-malarial drugs with long elimination half-life, such as lumefantrine, piperaquine, pyronaridine, and atovaquone, to improve the in vitro activity of atorvastatin against different $P$. falciparum strains to treat uncomplicated malaria.

\section{Methods}

\section{Strains of Plasmodium falciparum}

Thirteen parasite strains or clones from a wide panel of countries (Cambodia, Cameroon, Gabon, the Gambia, Indochina, Republic of Comoros, Republic of the Congo, Senegal, Sierra Leone, and Uganda) were maintained in culture in RPMI 1640 (Invitrogen, Paisley, UK) supplemented with $10 \%$ human serum (Abcys SA, Paris, France) and buffered with $25 \mathrm{mM}$ HEPES and $25 \mathrm{mM} \mathrm{NaHCO}_{3}$. Parasites were grown in type $\mathrm{A}^{+}$human red blood cells under controlled atmospheric conditions $\left(10 \% \mathrm{O}_{2}, 5 \%\right.$ $\mathrm{CO}_{2}$, and $85 \% \mathrm{~N}_{2}$ ) at $37^{\circ} \mathrm{C}$ with a humidity of $95 \%$. All strains were synchronized twice with sorbitol before use [18]. Clonality was verified using PCR genotyping of polymorphic genetic markers, msp1, msp2, and microsatellite loci $[19,20]$. The potentiation evaluation of each strain was assessed in three independent experiments, as previously described [21].

\section{Drugs}

Stock solutions were prepared by dilution in methanol for piperaquine, pyronaridine and atovaquone; and in ethanol for lumefantrine. Final concentrations ranged from 0.05 to $318 \mathrm{nM}$ for lumefantrine, 0.1 to $10,000 \mathrm{nM}$ for atovaquone, 0.16 to $100 \mathrm{nM}$ for pyronaridine and 0.78 to $994 \mathrm{nM}$ for piperaquine. A total of $25 \mu \mathrm{L}$ of stock solution of each concentration was distributed in duplicate or triplicate into Falcon 96-well flat bottom plates. Plates were dried overnight. Atorvastatin stock solution was prepared extemporately with $1 \%$ DMSO (v/v) in RPMI and diluted in sterile distilled water for final concentrations included between 0.006 and $32 \mu \mathrm{M}$. Aliquots of $25 \mu \mathrm{l}$ of atorvastatin solution were distributed into Falcon 96-well plates pre-dosed with anti-malarial agents.

\section{In vitro assay}

The $50 \%$ inhibitory concentration $\left(\mathrm{IC}_{50}\right)$, i.e., the drug concentration corresponding to $50 \%$ of the uptake of $3 \mathrm{H}$-hypoxanthine by the parasites in drug-free control wells, was determined by non-linear regression analysis of log-dose/response curves. Data were expressed as the geometric mean $\mathrm{IC}_{50}$, and 95\% confidence intervals (95\% CIs) were calculated. Each anti-malarial drug was serial diluted and combined with a static concentration of atorvastatin to obtain $\mathrm{IC}_{50}$ for each anti-malarial drug. Ten various atorvastatin concentrations were used to construct the isobolograms. Isobolograms were constructed by plotting a pair of fractional $\mathrm{IC}_{50} \mathrm{~s}$ for each combination of anti-malarial treatment and atorvastatin. Fractional $\mathrm{IC}_{50} \mathrm{~S}$ were calculated by dividing the atorvastatin fixed concentration by its $\mathrm{IC}_{50}$ alone, and these data were plotted on the horizontal axis. The corresponding fractional $\mathrm{IC}_{50} \mathrm{~S}$ of each classical anti-malarial treatment were calculated by dividing the combined $\mathrm{IC}_{50} \mathrm{~s}$ of each classical anti-malarial treatment with the atorvastatin by the $\mathrm{IC}_{50}$ of the anti-malarial treatment alone, and these data were plotted on the vertical axis. A straight diagonal isobologram indicates an additive effect. Curves above or below the diagonal indicate antagonistic or synergistic effects, respectively. Results close to the diagonal are considered to be additive.

\section{Statistical analysis}

The effects of atorvastatin at concentrations ranging from 0.1 to $1 \mu \mathrm{M}$, without intrinsic effects, were analysed with respect to the lumefantrine, piperaquine, pyronaridine, and atovaquone activity. These concentrations were relevant to atorvastatin plasma concentrations that are achievable in patients taking $80 \mathrm{mg}$ of atorvastatin daily (0.1 to $0.5 \mu \mathrm{M})$. Statistical analysis was performed using $\mathrm{R}$ 
software $^{\bullet}$ (version 2.10.1). The global Friedman test was used to compare the medians of different matched groups, and the Wilcoxon test was used to compare the medians of two matched under-groups.

\section{Results}

Atorvastatin showed additive effects with piperaquine, lumefantrine and pyronaridine (Figure 1).

Static concentration of atorvastatin affected significantly the in vitro activity of lumefantrine and piperaquine. The average $\mathrm{IC}_{50}$ values of lumefantrine decreased significantly from $31.9 \mathrm{nM}$ to $28.1 \mathrm{nM}$ (a decrease of $11 \%$ ) in combination with $0.12 \mu \mathrm{M}$ of atorvastatin, $26.3 \mathrm{nM}$ (a decrease of $17.6 \%$ ) in combination with $0.25 \mu \mathrm{M}$ of atorvastatin, $24.6 \mathrm{nM}$ (a decrease of 24.8\%) in combination with
$0.5 \mu \mathrm{M}$ of atorvastatin and $20.5 \mathrm{nM}$ (a decrease of 35.7\%) in combination with $1 \mu \mathrm{M}$ of atorvastatin, at atorvastatin plasma concentrations expected from clinical observations in patients taking $80 \mathrm{mg}$ of atorvastatin daily (Table 1).

The average $\mathrm{IC}_{50}$ values of piperaquine decreased significantly from $61.1 \mathrm{nM}$ to $52.5 \mathrm{nM}$ (a decrease of 14.1\%) in combination with $0.5 \mu \mathrm{M}$ of atorvastatin and $51.2 \mathrm{nM}$ (a decrease of 16.2\%) in combination with $1 \mu \mathrm{M}$ of atorvastatin.

Atorvastatin did not significantly affect the $\mathrm{IC}_{50}$ values of pyronaridine or atovaquone.

\section{Discussion}

Atorvastatin improved strongly the in vitro activity of dihydroartemisinin [10], mefloquine [8], quinine [9], and
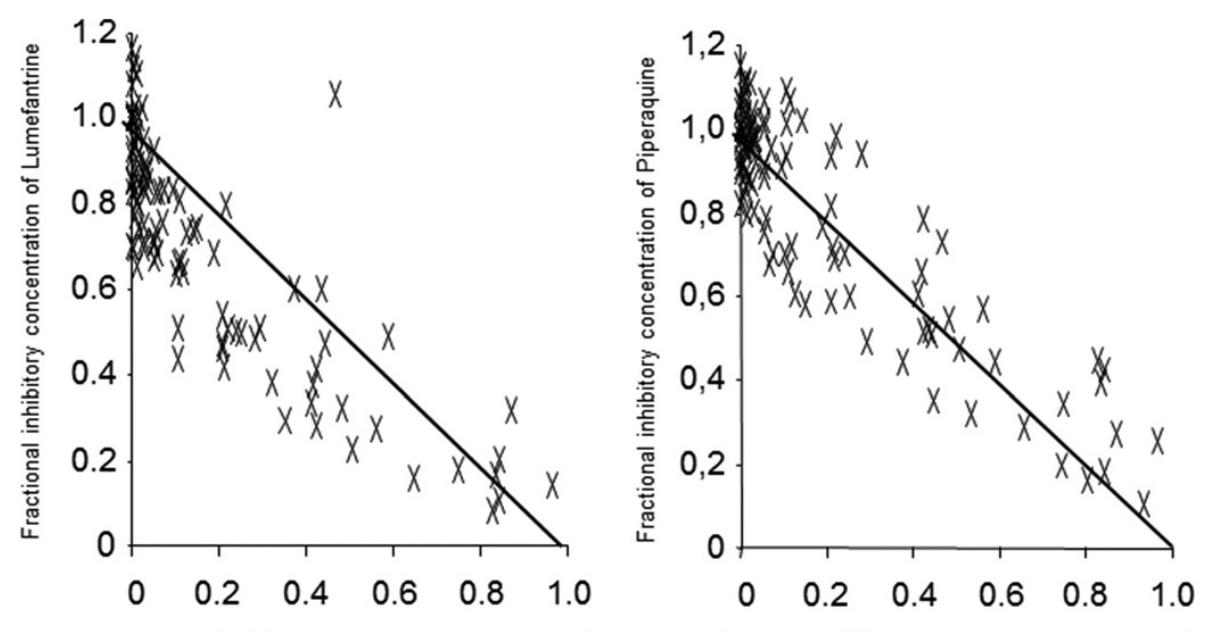

Fractional inhibitory concentration of Atorvastatin

Fractional inhibitory concentration of Atorvastatin

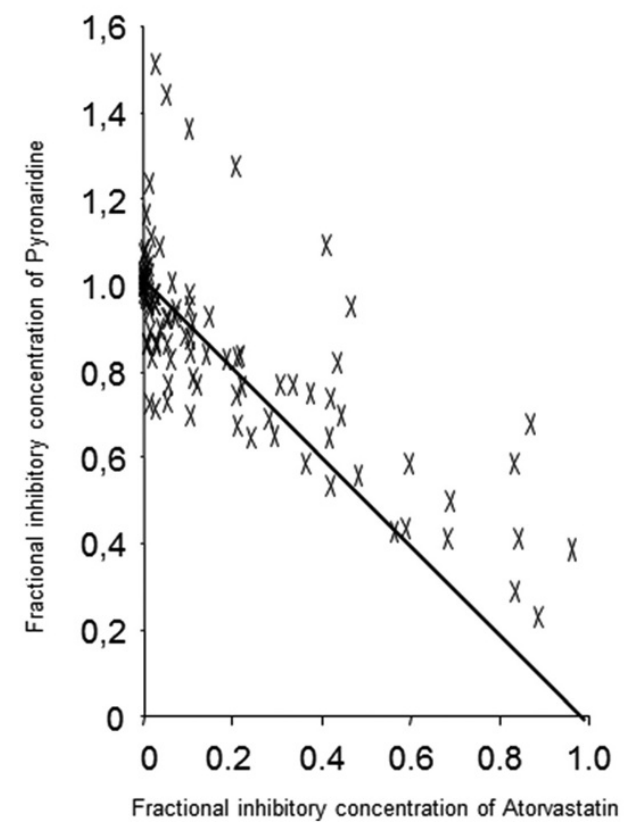

Figure 1 In vitro combinations of atorvastatin with lumefantrine, piperaquine and pyronaridine against 13 Plasmodium falciparum strains. 
Table 1 Inhibitory activities of lumefantrine, piperaquine, pyronaridine and atovaquone alone and in combination with atorvastatin against 13 strains of Plasmodium falciparum

\begin{tabular}{|c|c|c|c|c|c|c|c|c|}
\hline \multirow[t]{2}{*}{ Anti-malarial drugs } & \multicolumn{2}{|c|}{ Lumefantrine } & \multicolumn{2}{|c|}{ Piperaquine } & \multicolumn{2}{|c|}{ Pyronaridine } & \multicolumn{2}{|c|}{ Atovaquone } \\
\hline & $\mathrm{IC}_{50}$ mean $(\mathrm{nM})$ & P-value & $\mathrm{IC}_{50}$ mean $(\mathrm{nM})$ & P-value & $\mathrm{IC}_{50}$ mean $(\mathrm{nM})$ & P-value & $\mathrm{IC}_{50}$ mean $(\mu \mathrm{M})$ & P-value \\
\hline Alone & $31.9 \pm 15.1$ & & $61.1 \pm 15.5$ & & $30.3 \pm 9.6$ & & $3.79 \pm 2.0$ & \\
\hline$+0.12 \mu \mathrm{M}$ Atorvastatin & $28.1 \pm 15.1$ & 0.0068 & $59.5 \pm 19.7$ & NS & $28.9 \pm 9.2$ & NS & $3.35 \pm 1.5$ & NS \\
\hline$+0.25 \mu \mathrm{M}$ Atorvastatin & $26.3 \pm 12.4$ & 0.0019 & $61.7 \pm 18.7$ & NS & $29.1 \pm 10.1$ & NS & $3.35 \pm 1.6$ & NS \\
\hline$+0.5 \mu \mathrm{M}$ Atorvastatin & $24.6 \pm 11.7$ & 0.0019 & $52.5 \pm 17.5$ & 0.0146 & $28.4 \pm 10.2$ & NS & $3.23 \pm 1.3$ & NS \\
\hline$+1 \mu \mathrm{M}$ Atorvastatin & $20.5 \pm 11.0$ & 0.0009 & $51.2 \pm 19.2$ & 0.0244 & $26.9 \pm 10.0$ & NS & $2.93 \pm 1.3$ & NS \\
\hline
\end{tabular}

NS if P-value $>0.05$.

methylene blue [11] and less strongly those lumefantrine and piperaquine. Atorvastatin demonstrated antagonistic effects with anti-malarial drugs whose resistance involves the $P$. falciparum chloroquine resistance transporter gene $(p f c r t)$, such as chloroquine, monodesethylamodiaquine [9]. In addition, atorvastatin didn't affect significantly the in vitro activity of pyronaridine whose resistance seems to interact also with pfcrt (unpublished observations). A decrease in P. falciparum susceptibility to lumefantrine, mefloquine or dihydroartemisinin is associated with polymorphisms in the genes encoding the multidrug resistance (MDR)-like proteins, such as Pgh1, encoded by pfmdr1 (P. falciparum multidrug resistance 1 ), or in copy numbers of this gene [22-25]. Atorvastatin is an inhibitor of the human phosphoglycoprotein (PgP), an efflux protein involved in cancer cells [26-28]. Pgh1 could be a target for atorvastatin in P. falciparum parasites. However, in vitro responses to piperaquine seem to be not associated with polymorphisms in pfcrt gene [29] and in pfmdr1 [30] or copy number of $p f m d r 1$ [31], but associated with repeat polymorphisms in the low-complexity regions of a $P$. falciparum $\mathrm{ABC}$ transporter, pfmdr6 [32]. Atorvastatin seems to improve the in vitro activity of anti-malarial drugs whose resistance involves preferentially $A B C$ transporters such as pfmdr1 and pfmdr6 and don't affect or reduce the activity of drugs whose resistance involves preferentially $p f c r t$.

Atorvastatin given with mefloquine and dihydroartemisinin prevents cerebral malaria in a mouse model $[16,17]$. However, the mice that did not die of cerebral malaria died of severe anaemic malaria. Atorvastatin strongly protects endothelial cells against $P$. falciparuminduced collateral damage, cell apoptosis and endothelial barrier permeabilization [33]. Atorvastatin can be used to reduce $P$. falciparumcyto-adherence to endothelial cells; cyto-adherence and the inflammatory burst are the key events of pathogenesis in severe human malaria. In mice with Plasmodium berghei ANKA cerebral malaria, lovastatin reduces pro-inflammatory cytokines in the brain and prevents cognitive impairment [34].

Another hypothesis that could explain differences in vitro activity and in vivo efficacy is the role the cytochrome
P450 enzyme. Most of the anti-malarial drugs are metabolised by the cytochrome P450 enzyme. Chloroquine, quinine, mefloquine, amodiaquine, lumefantrine, piperaquine, artemisinin derivatives and atorvastatin are metabolised by CYP3A4/A5 [35,36]. Artesunate and artemisinin are also metabolised by CYP2A6 and CYP2B6 [35]. Dihydroartemisinin is metabolised by UGT1A9 and UGT2B7 [35]. In addition, chloroquine and amodiaquine are metabolised by CYP2C8 [35]. Atorvastatin induces the activity of CYP2C8 and that of CYP3A4 but to a lesser way [37]. By increasing the P450 activity, atorvastatin could increase the catabolism of some anti-malarial drugs and reduce or sometimes increase (proguanil) the efficacy of the drug.

Even though in vitro data indicate that atorvastatin improved the activity of lumefantrine and piperaquine, the same may not necessarily be true in vivo. Piperaquine, a new drug with long terminal elimination halflife, is currently a very promising anti-malarial drug. These observations support calls for an in vivo evaluation of combination of atorvastatin with lumefantrine and piperaquine in a mouse model to treat uncomplicated malaria.

Competing interests

All authors declare that they have no competing interests.

Authors' contributions

$J D, H S, R A$, and EB carried out the in vitro tests. BP conceived and coordinated the study. JD and BP analysed the data. JD and BP drafted the manuscript. All the authors read and approved the final manuscript.

\section{Acknowledgements}

This study was supported by the Délégation Générale pour l'Armement (grant no PDH-2-NRBC-4-B1-402).

\section{Author details}

'Unité de Parasitologie et d'Entomologie, Département de Microbiologie, Institut de Recherche Biomédicale des Armées, Brétigny sur Orge, France. 2Unité de Parasitologie, Département d'Infectiologie de Terrain, Institut de Recherche Biomédicale des Armées, Marseille, France. ${ }^{3}$ Unité de Recherche sur les Maladies Infectieuses et Tropicales Emergentes, UM 63, CNRS 7278 IRD 198, Inserm 1095, Aix Marseille Université, Marseille, France. ${ }^{4}$ Service des Maladies Infectieuses, Hôpital d'Instruction des Armées Laveran, Marseille, France. ${ }^{5}$ Centre National de Référence du Paludisme, Marseille, France. 
Received: 24 November 2013 Accepted: 20 May 2014

Published: 25 May 2014

\section{References}

1. Le Bras J, Musset L, Clain J: Antimalarial drug resistance. Med Mal Infect 2006, 36:401-405.

2. Noedl H, Se Y, Schaecher K, Smith BL, Socheat D, Fukuda MM: Evidence of artemisinin-resistant malaria in western Cambodia. N Engl J Med 2008, 359:2619-2620.

3. Dondorp AM, Nosten F, Yi P, Das D, Phyo AP, Tarning J, Lwin KM, Ariey F, Hanpithakpong W, Lee SJ, Ringwald P, Silamut K, Imwrong M, Chotivanish K, Lim P, Herdman T, An SS, Yeung S, Singhasivanon P, Day NPJ, Lindegardh $\mathrm{N}$, Socheat D, White NJ: Artemisinin resistance in Plasmodium falciparum malaria. N Engl J Med 2009, 361:455-467.

4. Amaratunga C, Sreng S, Suon S, Phelps ES, Stepniewska K, Lim P, Zhou C, Mao S, Anderson JM, Lindegardh N, Jiang H, Song J, Su XZ, White NJ, Dondorp AM, Anderson TCJ, Fay MP, Mu J, Duong S, Fairhurst RM: Artemisinin-resistant Plasmodium falciparum in Pursat province, western Cambodia: a parasite clearance rate study. Lancet Infect Dis 2012, 12:851-858

5. White NJ: Preventing antimalarial drug resistance through combinations. Drug Resist Updat 2001, 1:3-9

6. Pradines B, Torrentino-Madamet M, Fontaine A, Henry M, Baret E, Mosnier J, Briolant S, Fusai T, Rogier C: Atorvastatin is 10-fold more active in vitro than other statins against Plasmodium falciparum. Antimicrob Agents Chemother 2007, 51:2654-2655

7. Parquet $\mathrm{V}$, Briolant $\mathrm{S}$, Torrentino-Madamet $\mathrm{M}$, Henry M, Almeras L, Amalvict $R$, Baret $E$, Fusai T, Rogier C, Pradines B: Atorvastatin is a promising partner for antimalarial drugs in treatment of Plasmodium falciparum malaria. Antimicrob Agents Chemother 2009, 53:2248-2252.

8. Wurtz N, Briolant S, Gil M, Parquet V, Henry M, Baret E, Amalvict R, Almeras $L$, Rogier $C$, Pradines B: Synergy of mefloquine activity with atorvastatin, but not chloroquine and monodesethylamodiaquine, and association with the pfmdr1 gene. J Antimicrob Chemother 2010, 65:1387-1394

9. Parquet V, Henry M, Wurtz N, Dormoi J, Briolant S, Gil M, Baret E, Amalvict R, Rogier C, Pradines B: Atorvastatin as a potential anti-malarial drug: in vitro synergy in combinational therapy with quinine against Plasmodium falciparum. Malar J 2010, 9:139.

10. Savini H, Souraud JB, Briolant $S$, Baret E, Amalvict R, Rogier C, Pradines B: Atorvastatin as a potential antimalarial drug: in vitro synergy in combinational therapy with dihydroartemisinin. Antimicrob Agents Chemother 2010, 54:966-967.

11. Dormoi J, Pascual A, Briolant S, Amalvict R, Charras S, Baret E, Huyghues des Etages E, Feraud M, Pradines B: Proveblue (Methylene Blue) as antimalarial agent: In vitro synergy with dihydroartemisinin and atorvastatin. Antimicrob Agents Chemother 2012, 56:3467-3469.

12. Borek-Dohalsky V, Huclova J, Barrett B, Nemec B, Ulc I, Jelinek I: Validated HPLC-MS-MS method for simultaneous determination of atorvastatin and 2-hydroxyatorvastatin in human plasma-pharmacokinetic study. Anal Bioanal Chem 2006, 386:275-285.

13. Bienvenu AL, Picot S: Statins alone are ineffective in cerebral malaria but potentiate artesunate. Antimicrob Agents Chemother 2008, 52:4203-4204.

14. Helmers AJ, Gowda DC, Kain KC, Liles WC: Statins fail to improve outcome in experimental cerebral malaria and potentiate Toll-like receptormediated cytokine production by murine macrophages. Am J Trop Med Hyg 2009, 81:631-637.

15. Dormoi J, Briolant S, Desgrouas C, Pradines B: Impact of methylene blue and atorvastatin combination therapy on the apparition of cerebral malaria in a murine model. Malar J 2013, 12:127.

16. Souraud JB, Briolant S, Dormoi J, Mosnier J, Savini H, Baret E, Amalvict Rs Soulard R, Rogier C, Pradines B: Atorvastatin treatment is effective when used in combination with mefloquine in an experimental cerebral malaria murine model. Malar J 2012, 11:13.

17. Dormoi J, Briolant S, Pascual A, Desgrouas C, Travaillé C, Pradines B: Improvement of the efficacy of dihydroartemisinin with atorvastatin in an experimental cerebral malaria murine model. Malar J 2013, 12:302.

18. Lambros C, Vanderberg JP: Synchronization of Plasmodium falciparumerythrocytic stages in culture. J Parasitol 1979, 65:418-420
19. Bogreau H, Renaud F, Bouchiba H, Durand P, Assi SB, Henry MC, Garnotel E, Pradines B, Fusai T, Wade B, Adehossi E, Parola P, Kamil MA, Puijalon O, Rogier C: Genetic diversity and structure of African Plasmodium falciparum populations in urban and rural areas. Am J Trop Med Hyg 2006, 74:953-959.

20. Henry M, Diallo I, Bordes J, Ka S, Pradines B, Diatta B, M'Baye PS, Sane M, Thiam M, Gueye PM, Wade B, Touze JE, Debonne JM, Rogier C, Fusai T: Urban malaria in Dakar, Senegal: chemosusceptibility and genetic diversity of Plasmodium falciparum isolates. Am J Trop Med Hyg 2006, 75:146-151.

21. Henry M, Alibert S, Baragatti M, Mosnier J, Baret E, Amalvict R, Legrand E, Fusai T, Barbe J, Rogier C, Pagès JM, Pradines B: Dihydroanthracene derivatives reverse in vitro quinoline resistance in Plasmodium falciparum malaria. Med Chem 2008, 4:426-437.

22. Dokomajilar C, Nsobya SL, Greenhouse B, Rosenthal PJ, Dorsey G Selection of Plasmodium falciparum pfmdr1 alleles following therapy with artemether-lumefantrine in an area of Uganda where malaria is highly endemic. Antimicrob Agents Chemother 2006, 50:1893-1895.

23. Lim P, Akler AP, Khim N, Shah NK, Incardona S, Doung S, Yi P, Bouth DM, Bouchier C, Puijalon OM, Meshnick SR, Wongsrichanalai C, Fandeur T, Le Bras J, Ringwald P, Ariey F: Pfmdr1 copy number and artemisinin derivatives combination therapy failure in falciparum malaria in Cambodia. Malar J 2009, 8:11.

24. Price RN, Uhlemann AC, Brockman A, McReady R, Ashley E, Phaipun L, Patel R, Laing K, Looareesuwan S, White NJ, Nosten F, Krishna S: Mefloquine resistance in Plasmodium falciparum and increased pfmdr1 gene copy number. Lancet 2004, 364:438-447.

25. Sidhu ABS, Uhlmann AC, Valderramos SG, Valderramos JC, Krishna S, Fidock DA: Decreasing pfmdr1 copy number in Plasmodium falciparum malaria heightens susceptibility to mefloquine, lumefantrine, halofantrine, quinine, and artemisinin. J Infect Dis 2006, 194:528-535.

26. Holtzman CW, Wiggins BS, Spinler SA: Role of P-glycoprotein in statin drug interactions. Pharmacotherapy 2006, 26:1601-1607.

27. Wang E, Casciano CN, Clement RP, Johnson WW: HMG-CoA reductase inhibitors (statins) characterized as direct inhibitors of P-glycoprotein Pharm Res 2001, 18:800-806.

28. Wu X, Whitfield LR, Stewart BH: Atorvastatin transport in the Caco-2 cell model: contributions of P-glycoprotein and the proton-monocarboxylic acid co-transporter. Pharm Res 2000, 17:209-215.

29. Pascual A, Madamet M, Bertaux L, Amalvict R, Benoit N, Travers D, Cren J, Taudon N, Rogier C, Parzy D, Pradines B: In vitro piperaquine susceptibility is not associated with Plasmodium falciparumchloroquine resistance transporter gene. Malar J 2013, 12:431.

30. Hao M, Jia D, Li Q, He Y, Yuan L, Xu S, Chen K, Wu J, Shen L, Sun L, Zhao H, Yang Z, Cui L: In vitro sensitivities of Plasmodium falciparum isolates from the China-Myanmar border to piperaquine and association with polymorphisms in candidate genes. Antimicrob Agents Chemother 2013, 57:1723-1729.

31. Lim P, Dek D, Try V, Eastman RT, Chy S, Sreng S, Suon S, Mao S, Sopha C, Sam B, Ashley EA, Miotto O, Dondorp AM, White NJ, Su X-Z, Chuor Char M, Anderson JM, Amaratunga C, Menard D, Fairhurst RM: Ex vivo susceptibility of Plasmodium falciparum to antimalarial drugs in Western, Northern, and Eastern Cambodia, 2011-2012: Association with molecular markers. Antimicrob Agents Chemother 2013, 57:5277-5283.

32. Okombo J, Abdi Al, Kiara SM, Mwai L, Pole L, Sutherland CJ, Nzila A, Ochola-Oyier LI: Repeat polymorphisms in the low-complexity regions of Plasmodium falciparum $\mathrm{ABC}$ transporters and associations with in vitro antimalarial responses. Antimicrob Agents Chemother 2013, 57:6196-6204.

33. Taoufiq Z, Pino P, N'Dilimabaka N, Arrouss I, Assi S, Soubrier F, Rebollo A, Mazier D: Atorvastatin prevents Plasmodium falciparum cytoadherence and endothelial damage. Malar J 2011, 10:52.

34. Reis PA, Estato V, da Silva TI, d'Avila JC, Siqueira LD, Assis EF, Bozza PT, Bozza FA, Tibiriça EV, Zimmerman GA, Castro-Faria-Neto HC: Statins decrease neuroinflammation and prevent cognitive impairment after cerebral malaria. PLoS Pathog 2012, 8:e1003099.

35. Kerb R, Fux R, Morike K, Kremsner PG, Gil JP, Gleiter CH, Schwab M: Pharmacogenetics of antimalarial drugs: effect on metabolism and transport. Lancet 2009, 9:760-774. 
36. Lee TM, Huang L, Johnson MK, Lizak P, Kroetz D, Aweeka F, Parikh S: In vitro metabolism of piperaquine is primarily mediated by CYP3A4. Xenobiotica 2012, 42:1088-1095.

37. Fiedt DM, Klein K, Hofmann U, Riedmaier S, Knobeloch D, Thasler WE,

Weiss TS, Schwab M, Zanger UM: Profiling induction of cytochrome P450 enzyme activity by statins using a new liquid chromatography-tandem mass spectrometry coktail assay in human hepatocytes. Drug Metabolism Disposition 2010, 38:1589-1597.

doi:10.1186/1475-2875-13-189

Cite this article as: Dormoi et al: In vitro interaction of lumefantrine and piperaquine by atorvastatin against Plasmodium falciparum. Malaria

Journal 2014 13:189.

\section{Submit your next manuscript to BioMed Central and take full advantage of:}

- Convenient online submission

- Thorough peer review

- No space constraints or color figure charges

- Immediate publication on acceptance

- Inclusion in PubMed, CAS, Scopus and Google Scholar

- Research which is freely available for redistribution 